\title{
Avaliação do uso de anestésico tópico por cirurgiões dentistas professores de uma universidade particular do Nordeste Brasileiro
}

Therezinha de Jesus Gurgel Araújo, Danielle Frota de Albuquerque 1, Márcia Vieira Barreira Barroso 1, Heliene Linhares Matos 1, Israel Leal Cavalcante 1, José Rômulo de Medeiros 1, Fernando André Campos Viana 1, Sergio Luís da Silva Pereira 1, Jonas Nogueira Ferreira Maciel Gusmão 2, Bruno Frota Amora Silva 1, 2, *

${ }^{1}$ Universidade de Fortaleza, Ceará, CE, Brasil.

${ }^{2}$ Santa Casa de Misericórdia de Fortaleza, Ceará, CE, Brasil.

*Autor correspondente: Bruno Frota Amora Silva. Av. Washington Soares, 1321 - Edson Queiroz. CEP: 60811-905 - Ceará, CE, Brasil.

Aprovação em Comitê de Ética (if necessary): O projeto de pesquisa foi encaminhado e aprovado pelo Comitê de Ética em Pesquisa (CEP) da Universidade de Fortaleza (UNIFOR) sob o número de parecer 3.661.550.

Recebido em: Nov 10, 2021. Aceito em: Nov 17, 2021. Disponível online: Nov 22, 2021.

\section{Resumo}

A dor causada pela inserção da agulha durante a anestesia local está ligada à ansiedade do paciente no momento do atendimento. Sendo assim, os anestésicos tópicos foram criados com o objetivo de diminuir a sensação dolorosa durante esse procedimento. O presente estudo teve como objetivo principal avaliar a utilização da anestesia tópica por cirurgiões dentistas, antes da administração da anestesia local. Avaliou-se o uso de anestésicos tópicos através de uma coleta de dados por meio de formulário eletrônico, respondido por 53 Cirurgiões Dentistas, professores de uma Universidade de rede particular do estado do Ceará. Por meio do estudo foi possível perceber que $47 \%$ dos Dentistas sempre utilizam a anestesia tópica, tendo preferência pelo tipo gel (89\%), ao invés do Spray (7\%). Múltiplos fatores podem ser responsáveis por uma confusão referente à eficácia do anestésico tópico: distinção da área da aplicação, secagem preliminar da superfície, o tempo de aplicação, método de avaliação da dor e tipo de produto. Concluiu-se que a maioria dos profissionais faz uso da anestesia tópica, principalmente na forma de gel, se destacando os endodontistas, dentistas restauradores, ortodontistas e protesistas. Além disso, indivíduos com mais tempo de formados utilizam anestésicos tópicos mais frequentemente e da forma mais correta.

Palavras-chave: Anestesia Dentária; Administração Tópica; Lidocaína; Benzocaína.

\section{Introdução}

Na área odontológica, a dor pode estar relacionada a doenças que afetam a cavidade oral ou a algum procedimento odontológico. Embora seja uma experiência desagradável resultante do 
dano tecidual, também é uma resposta subjetiva, afetada por questões culturais, emocionais, de gênero e idade [1].

Estudos comprovaram que a dor causada pela inserção da agulha durante a anestesia local estava ligada à ansiedade do paciente no momento do atendimento. Dessa forma, os anestésicos tópicos foram criados com o objetivo de diminuir a sensação dolorosa durante esse procedimento [2].

$\mathrm{O}$ atendimento odontológico geralmente é fornecido após a anestesia local, para aliviar a dor durante o procedimento e o medo do paciente. Com o intuito de oferecer um atendimento mais seguro, é importante minimizar a dor associada à injeção inicial de anestésicos locais. Assim, fazse necessário aplicar primeiro um anestésico tópico na área onde a agulha será inserida, evitando imprevistos causados pelo estímulo doloroso [3].

Os anestésicos tópicos são definidos como fármacos que têm efeito analgésico quando usados próximos à área afetada e estão associados a concentrações aumentadas nos tecidos e concentrações séricas diminuídas. São amplamente utilizados na odontologia, principalmente no controle da dor associada à penetração da agulha na administração de anestesia local. Portanto, o medicamento administrado localmente exerce seu efeito na periferia, próximo ao local de aplicação, reduzindo a chance de efeitos colaterais adversos [2].

Os primeiros registros de anestesia tópica datam de meados do século XIX, sendo a cocaína a primeira substância a ser descoberta para essa finalidade. Albert Niemann, em 1860, assim como outros químicos, testou a composição recém-isolada e percebeu que a mesma fornecia uma sensação de entorpecimento da língua [4].

De acordo com De Freiras [5], o uso de anestésicos tópicos não deve ultrapassar 2 minutos, pois não foi observada diferença na dor durante a inserção da agulha com 2, 5 e 10 minutos. Para que um anestésico seja considerado eficaz, são necessárias as seguintes características: baixa toxicidade, nenhuma irritação aos tecidos, nenhum dano à estrutura nervosa, início rápido de ação, eficácia em relação à duração e reversibilidade, segundo Kumar, Chawla e Goyal [4].

Tanto os efeitos psicológicos como farmacológicos dos anestésicos tópicos no bloqueio da dor foram extensivamente estudados. Contudo, a literatura é contraditória. Alguns relatos dizem que a anestesia tópica ameniza a dor da injeção, enquanto outros afirmam que, em comparação com placebo, não há diferença. A área da cavidade oral onde é aplicado também pode influenciar no sucesso do anestésico tópico [5].

Fisiologicamente, o alívio da dor é alcançado reduzindo a permeabilidade temporária de íons de sódio nas 
membranas das células nervosas. No caso dos anestésicos tópicos, seu mecanismo de ação pode ser alterado por vários fatores, incluindo mudanças na composição do medicamento, $\mathrm{pH}$ e outros aditivos [6].

Conforme relataram Dimarco e Wetmore [7], as desvantagens dos anestésicos tópicos incluem: sabor desagradável, custo extra, dormência associada e longo tempo de espera por resultados ideais. Esses motivos levam alguns profissionais a evitar sua utilização ou reduzir o tempo de aplicação, mesmo não seguindo as recomendações do fabricante, por não trazer os benefícios desejados. Outrossim, os anestésicos tópicos não são utilizados da forma correta pela maioria dos cirurgiões dentistas.

As formulações de anestesia tópica podem ser usadas por via oral como géis, pomadas, soluções e adesivos. Os anestésicos mais comumente usados em preparações tópicas são benzocaína, lidocaína, cloridrato de tetracaína e uma combinação de benzocaína, tetrabenzil e tetracaína. A mistura eutética de lidocaína e prilocaína é especialmente projetada para anestesia da pele e também é usada para mucosa oral. Embora a lidocaína seja o padrão ouro, a benzocaína é bem conhecida por seu excelente desempenho em anestesia de superfície [8].

Segundo Malamed [9], é preciso ter alguns cuidados ao usar a benzocaína, pois a mesma é um éster que pode causar reações alérgicas. Como ela é absorvida sistemicamente, essas reações estão geralmente localizadas na área de aplicação, como a dermatite de contato, por exemplo. As reações alérgicas mediadas por anticorpos são mais raras. Devido ao risco de causar metemoglobinemia, não devem ser usados em crianças menores de dois anos de idade, pois essa síndrome pode levar à hipóxia dos tecidos e, em casos mais graves, à morte. Além disso, devem ser evitados em grandes cirurgias, em pacientes com doenças cardíacas, respiratórias ou metabólicas e em mulheres grávidas, pois o feto também corre o mesmo risco das crianças abaixo de dois anos.

A lidocaína também pode ser usada como anestésico tópico, com uma concentração que geralmente varia entre $2 \%$ a $10 \%$, ou em combinação com outros compostos. Estudos demonstraram que a mesma, como outros anestésicos de amida, pode causar reações alérgicas graves. Sua eficácia como agente tópico na odontologia é controversa e os resultados são heterogêneos. Houve comprovação de uma alta ocorrência de insucesso na redução de dor na injeção da mucosa palatina, sondagem gengival e injeção intraligamentar [2].

De acordo com Dave e Prabu [10], o uso do creme de Mistura Eutética de Anestésico Local (EMLA - lidocaínaprilocaína) foi também analisado, mas não há certeza da sua eficácia intraoral na odontologia. Outro estudo mais 
recente foi conduzido para avaliar a eficácia dos anestésicos tópicos e descobriu-se que o EMLA é muito eficaz como creme tópico oral. Vários pesquisadores estudaram medicamentos tópicos e outros sistemas de liberação de AL. Mais duas análises foram feitas para avaliar o efeito analgésico e a segurança do sistema de administração oral de lidocaína e concluíram que o adesivo atinge efeitos analgésicos significativos e, ao mesmo tempo, prova que os níveis sanguíneos são reduzidos em 10 a 14 vezes. Além disso, pode reduzir efetivamente a dor sentida ao inserir a agulha.

Apesar dos anestésicos tópicos serem usados frequentemente pelos dentistas anteriormente às infiltrações anestésicas locais, estudos mostram que sua eficácia tem variado bastante. As opiniões dos profissionais sobre essas substâncias também são divergentes. Sendo assim, pesquisas mais aprofundadas precisam ser feitas para buscar uma resposta mais plausível sobre seu uso na odontologia [11].

Observando $\mathrm{o}$ fato citado anteriormente, o presente trabalho teve o objetivo de analisar a utilização da anestesia tópica pelos cirurgiões dentistas antes da administração da anestesia local. Também procuramos identificar quais especialidades odontológicas utilizam com maior frequência, correlacionando o tempo de formação com esse uso correto. Foi determinada também qual a forma de apresentação do anestésico tópico mais usada e em quais técnicas anestésicas é mais frequente a sua aplicação.

\section{Metodologia}

O presente estudo foi do tipo observacional, transversal e quantitativo. Teve como amostra de estudo cirurgiões-dentistas professores de uma Universidade da rede particular do estado do Ceará, cadastrados no CRO-CE, com idade entre 30 e 80 anos. A população alvo constituiu-se de 80 professores. Utilizou-se como critério de exclusão cirurgiões-dentistas que não eram professores desta Universidade e respostas incompletas dos formulários.

Foi enviado via plataforma whatsapp ${ }^{\circledR}$ um texto de apresentação do estudo, seguido do link que direcionava para um website que continha o Termo de consentimento livre e esclarecido (TCLE) e o formulário de coleta de dados. Caso os profissionais estivessem de acordo em participar da pesquisa deveriam concordar assinando digitalmente o TCLE antes do preenchimento do formulário, resguardando assim os seus direitos e deveres, de acordo com a resolução 466/12 do CNS. Foi respeitado o sigilo dos mesmos e também garantido o livre poder de desistir de participar da pesquisa a qualquer momento.

Os participantes responderam a um questionário eletrônico com perguntas referentes a qual(is) especialidade(s) odontológica(s) o profissional possui; tempo de formação (em intervalos de 5 anos); frequência de 
uso do anestésico tópico; forma de apresentação do anestésico tópico (que é preferencialmente utilizada); técnica anestésica e a utilização do anestésico tópico seguindo corretamente as regras do fabricante.

Os dados obtidos foram analisados com o auxílio do programa SPSS (IBM, Estados Unidos da América) para Windows adotando uma confiança de $95 \%$. Os dados foram expressos em forma de frequência absoluta $\mathrm{e}$ percentual e associados por meio dos testes exato de Fisher ou qui-quadrado de Pearson.

Já que segundo Lee, os anestésicos locais podem induzir reações alérgicas, efeitos adversos e até mesmo overdose, os participantes terão benefício indireto, pois conhecendo melhor os aspectos da utilização do anestésico tópico pela comunidade odontológica, o cirurgião dentista terá mais informações para indicar ou não a utilização deste fármaco, de acordo com as variáveis estudadas nesta pesquisa [12].

\section{Results (Review)}

A pesquisa online foi composta de 53 participantes, onde $100 \%$ concordaram em colaborar com a mesma. Através dos resultados presentes na coleta de dados podemos observar como mostra no gráfico (Figura 01) que a variedade de especialidades odontológicas que fazem o uso de anestésicos tópicos é extremamente ampla, porém se destacam respectivamente os endodontistas com 20\%, dentistas restauradores com $13 \%$, ortodontistas também com $13 \%$ e protesistas com $10 \%$.

Podemos concluir também que os profissionais com mais tempo de formação são os que mais fazem uso do produto, liderando os que já são formados de 20 à 25 anos com $25 \%$ (Figura 02). Os que usam mais raramente são os formados há pouco tempo.

Outro fato mostrado por meio da pesquisa foi que a maioria dos cirurgiões dentistas sempre fazem o uso de anestesia tópica, alcançando uma taxa de 47\% (Figura 03). Além disso, é possível constatar que o tipo mais empregado é em gel, representando 89\% das respostas, enquanto $7 \%$ utilizam Spray e $4 \%$ não utilizam nenhuma das formas. É perceptível inclusive que há uma preferência por aplicar o produto em todas as técnicas de injeções, equivalente à $42 \%$ (Figura 04 ).

Quanto aos cuidados que antecedem a aplicação do anestésico tópico, vemos que a maioria dos profissionais têm essa cautela de secar a área onde será colocado o produto, expresso por $79 \%$ (Figura 05). Já em relação ao tempo de espera quando é manuseado a solução tópica até a injeção observamos que em maior parte esse passo é um pouco desprezado, tendo como maior taxa, 31 à 59 segundos com 38\%, enquanto o 
recomendado é 60 segundos ou mais

(Figura 06).

\section{Uso de anestésicos tópicos x Especialidade} odontológica

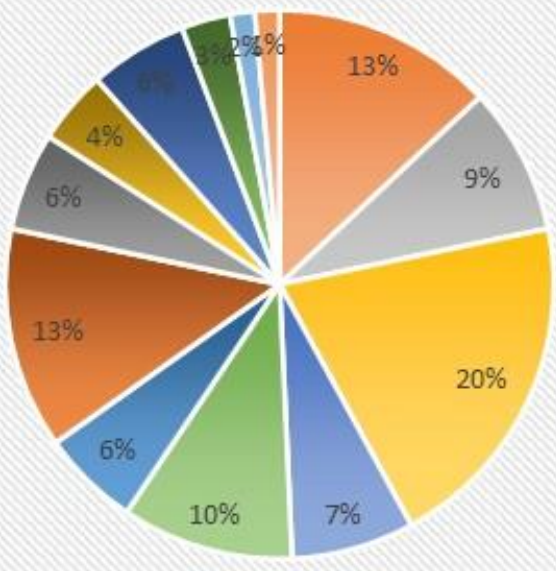

$$
\begin{aligned}
& \text { = Especialização } \\
& \text { = Ortodontia } \\
& \text { = Odontopediatria } \\
& \text { = Endodontia } \\
& \text { = Periodontia } \\
& \text { = Prótese } \\
& \text { = CTBMF } \\
& \text { = Dentistica } \\
& \text { = SaúdeColetiva }
\end{aligned}
$$

Figura 1. Uso de anestésicos tópicos x Especialidade odontológica.

\section{Tempo de formaçãox Uso de anestésico tópico}

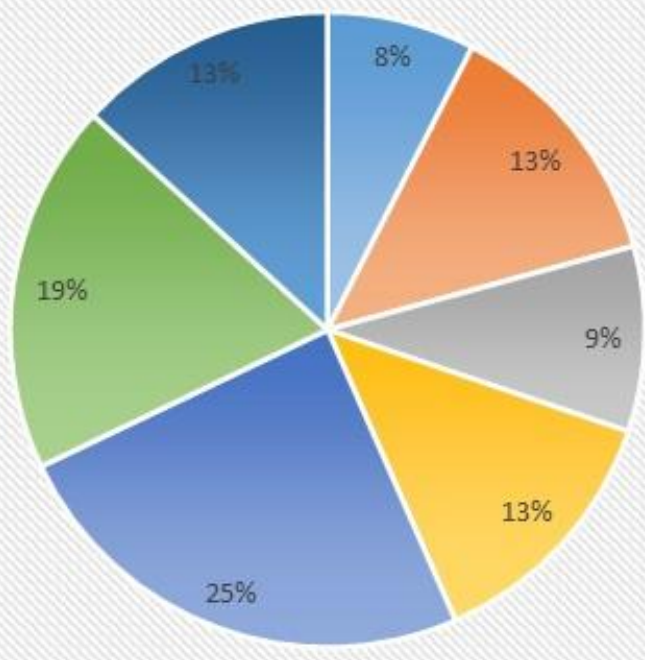

$$
\begin{aligned}
& =1-5 \text { anos } \\
& =5-10 \text { anos } \\
& =10-15 \text { anos } \\
& =15-20 \text { anos } \\
& =20-25 \text { anos } \\
& =25-30 \text { anos } \\
& =>30 \text { anos }
\end{aligned}
$$

Figura 2. Tempo de formação x Uso de anestésico tópico. 


\section{Frequência do uso de anestésicos tópicos}

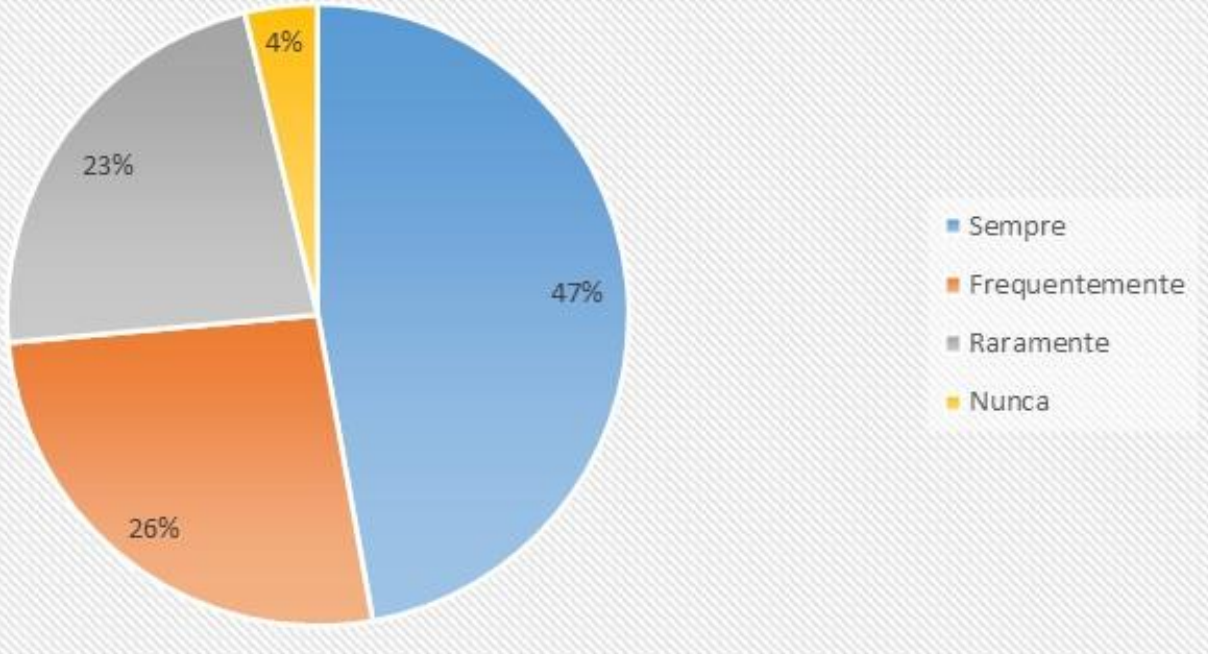

Figura 3. Frequência do uso de anestésicos tópicos.

\section{Técnica injeção anestésica x uso de anestésico tópico}

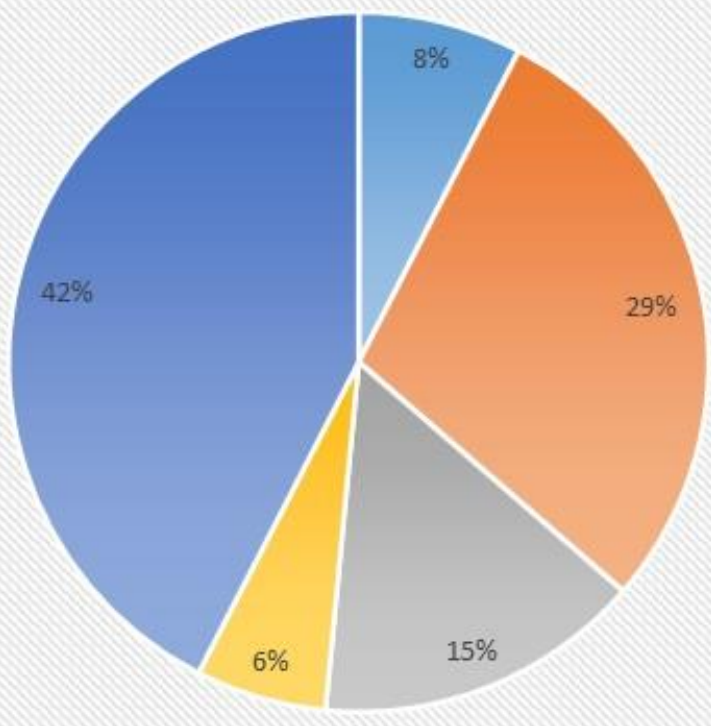

= Alveolar inferior

= Terminal infiltrativa

= Anestesias na região palatina

Nenhuma

m Todas

Figura 4. Técnica injeção anestésica x uso de anestésico tópico. 


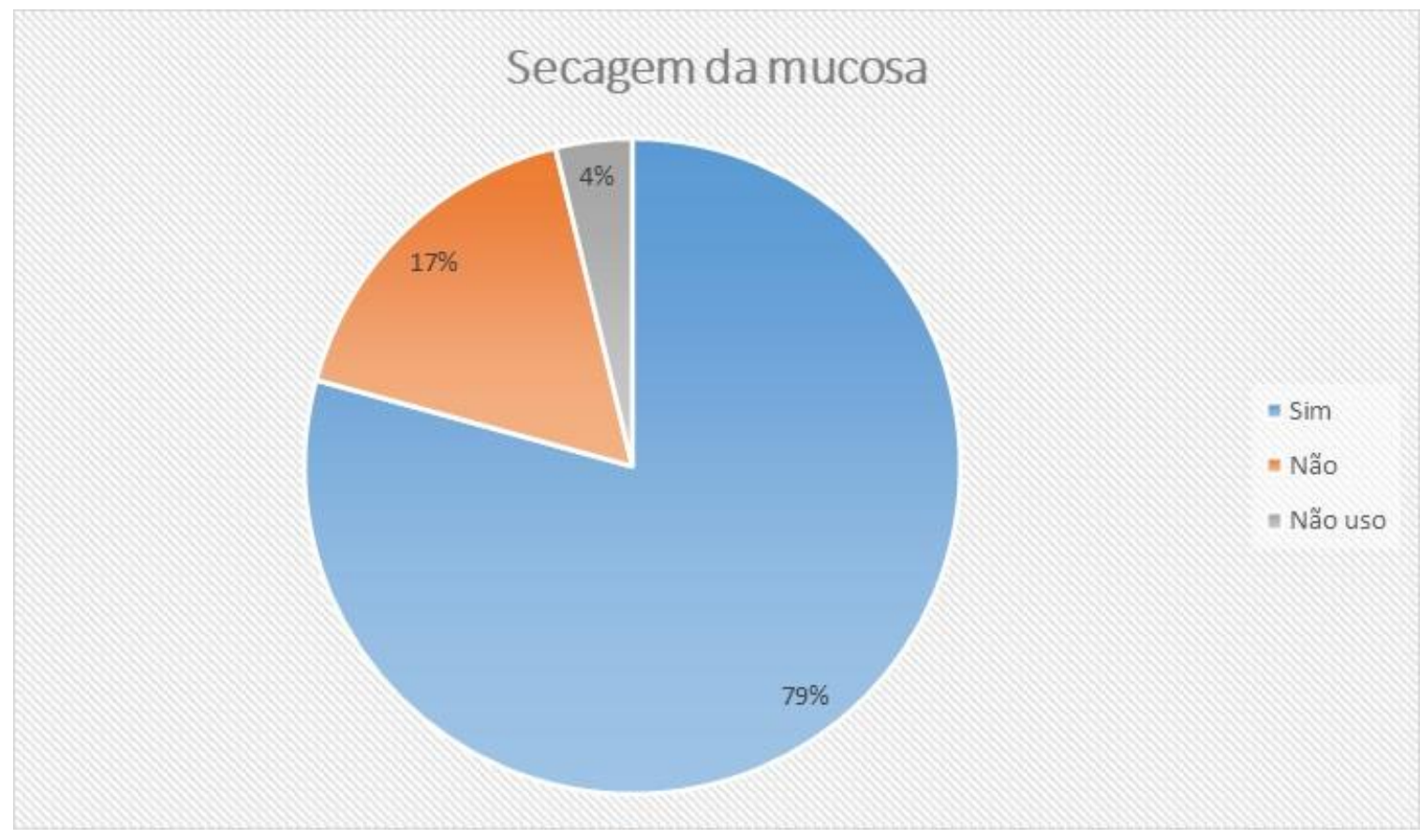

Figura 5. Secagem da mucosa.

\section{Tempo de espera para injeção anestésica}

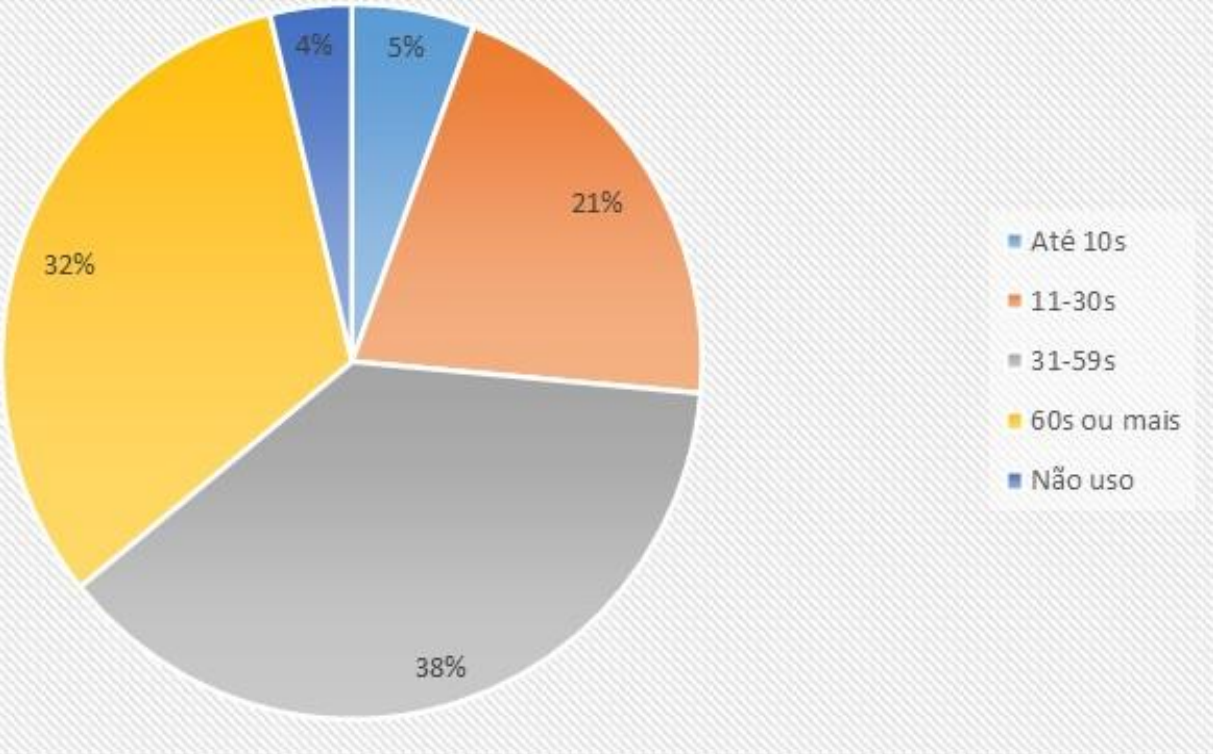

Figura 6. Tempo de espera para injeção anestésica. 
Sobre o grupo de pacientes em que o gel anestésico é mais utilizado estão as crianças correspondidas por $34 \%$ e pessoas ansiosas por $25 \%$ (Figura
7). Com relação à eficácia do AT, a maioria julga adequado (38\%) e eficaz (32\%) (Figura 8).

\section{Grupos de pacientes x uso de anestésicos tópicos}

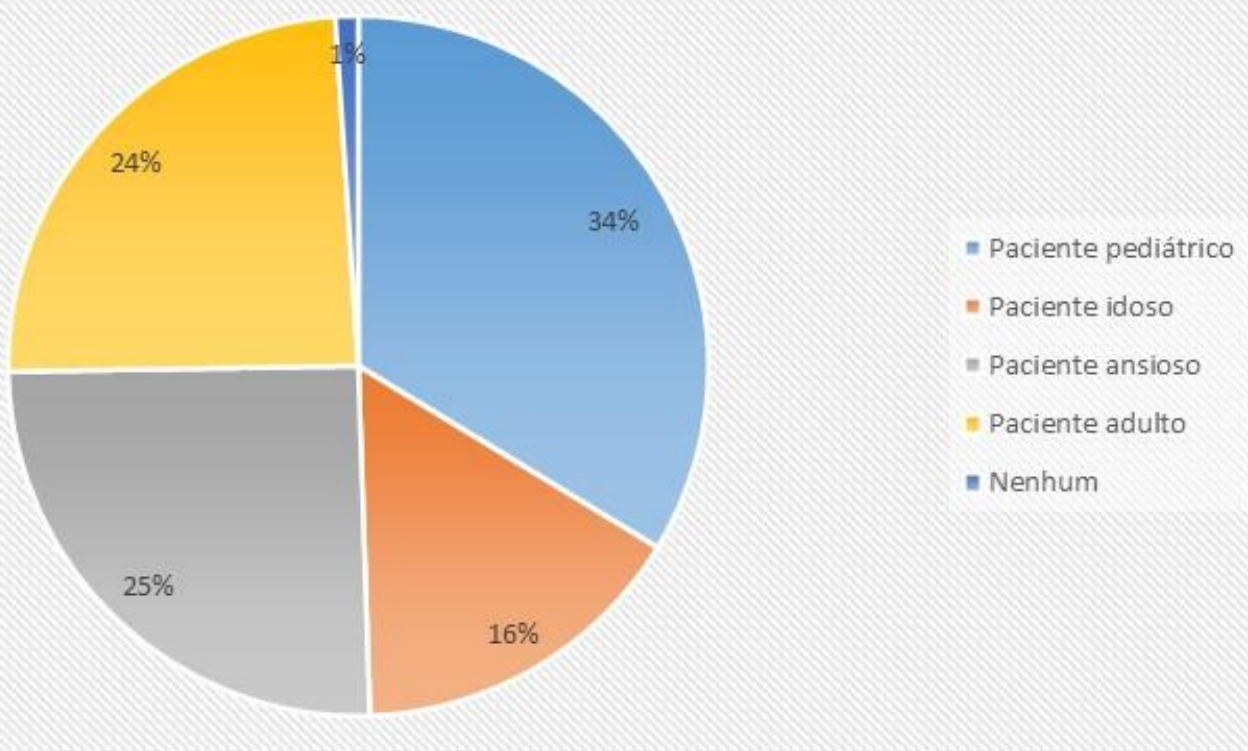

Figura 7. Grupos de pacientes x uso de anestésicos tópicos.

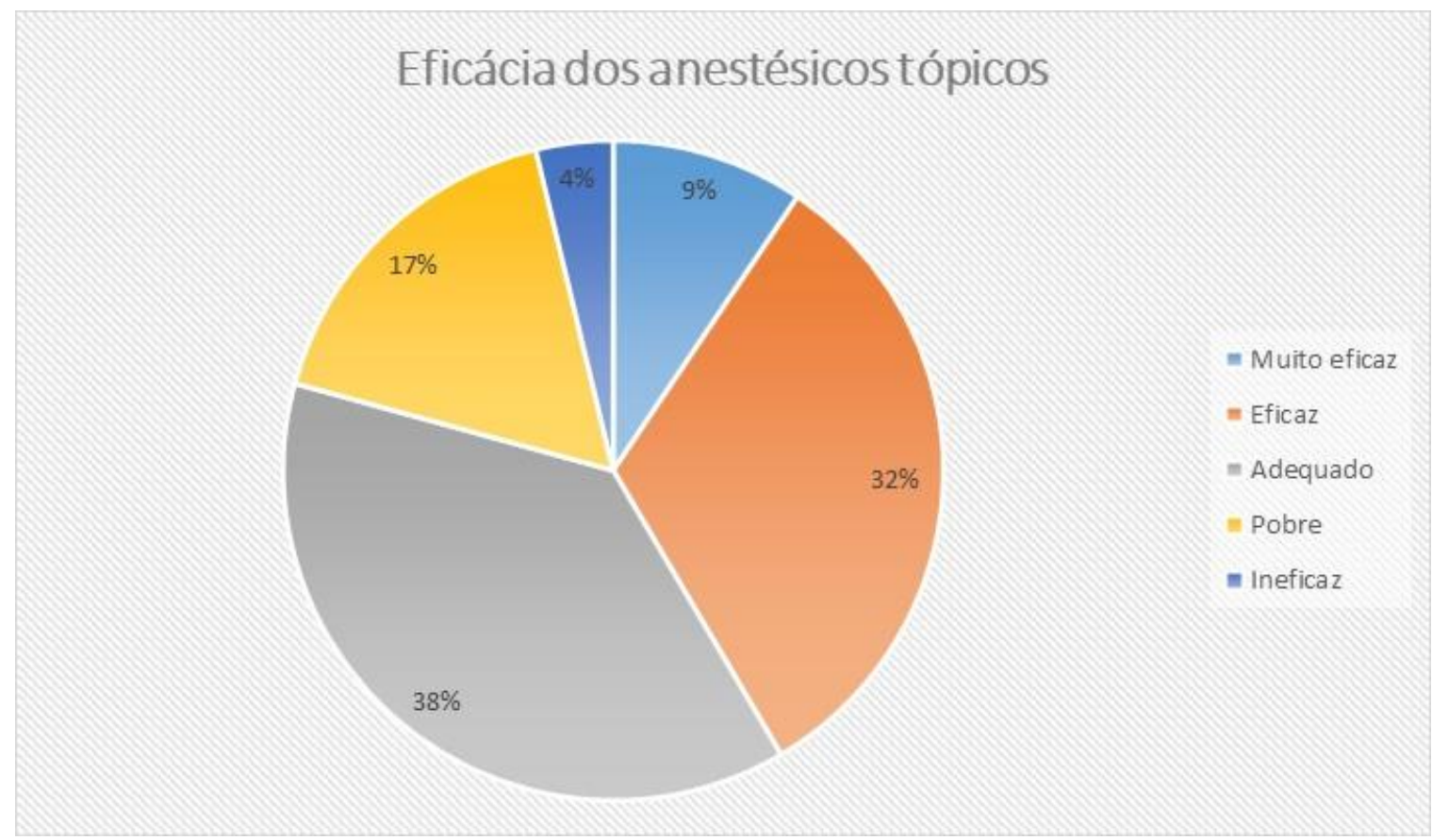

Figura 8. Eficácia dos anestésicos tópicos. 
Quando usado nas técnicas considera mais adequada ou eficaz terminal infiltrativa e na região palatina são os mais associados a ineficácia ou eficácia apenas adequada. Quem usa para todas as técnicas de injeções (Figura 9). É palpável a classificação da anestesia tópica como eficaz e adequado quando a mucosa é seca previamente (Figura 10).

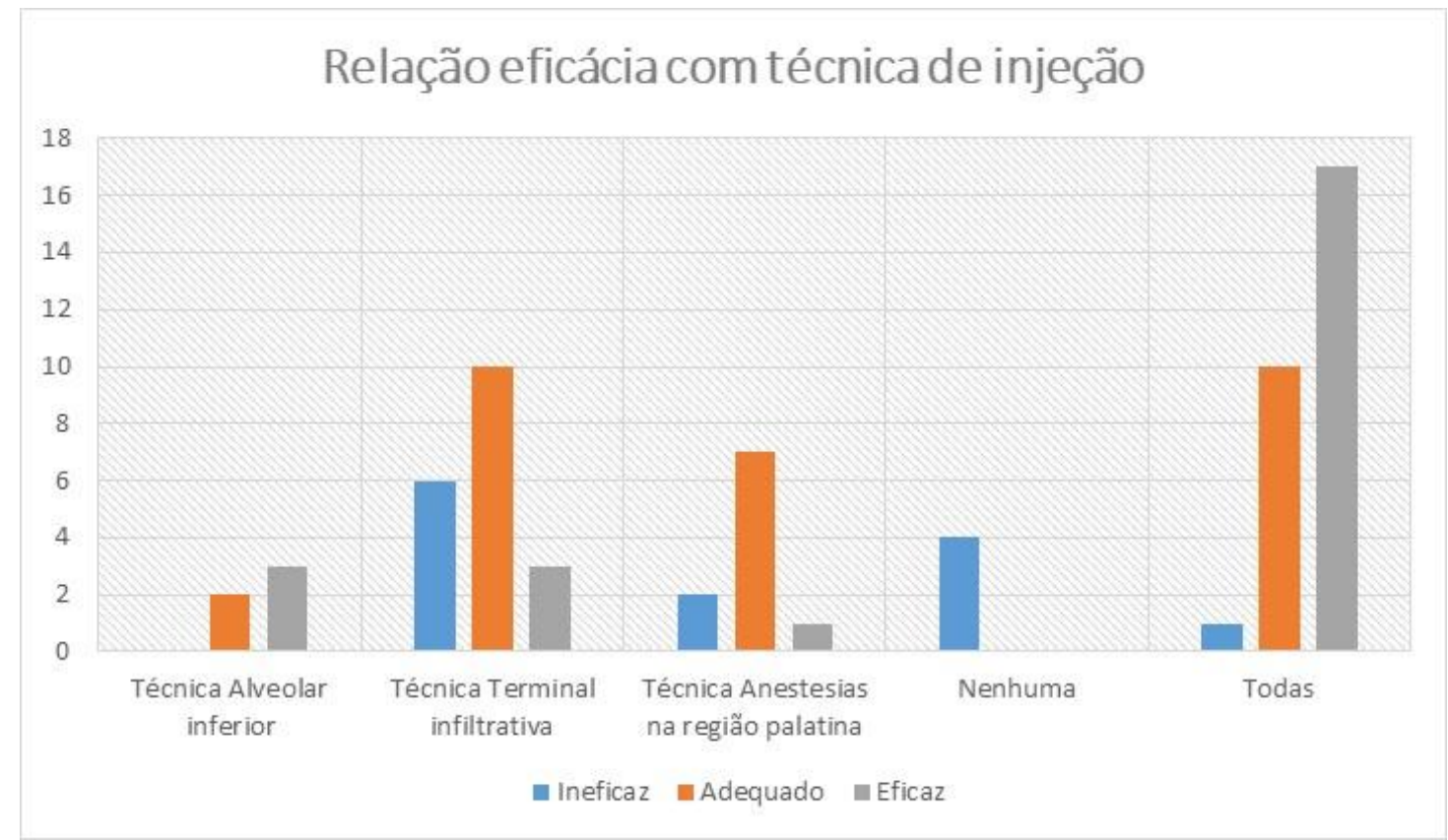

Figura 9. Relação eficácia com técnica de injeção.

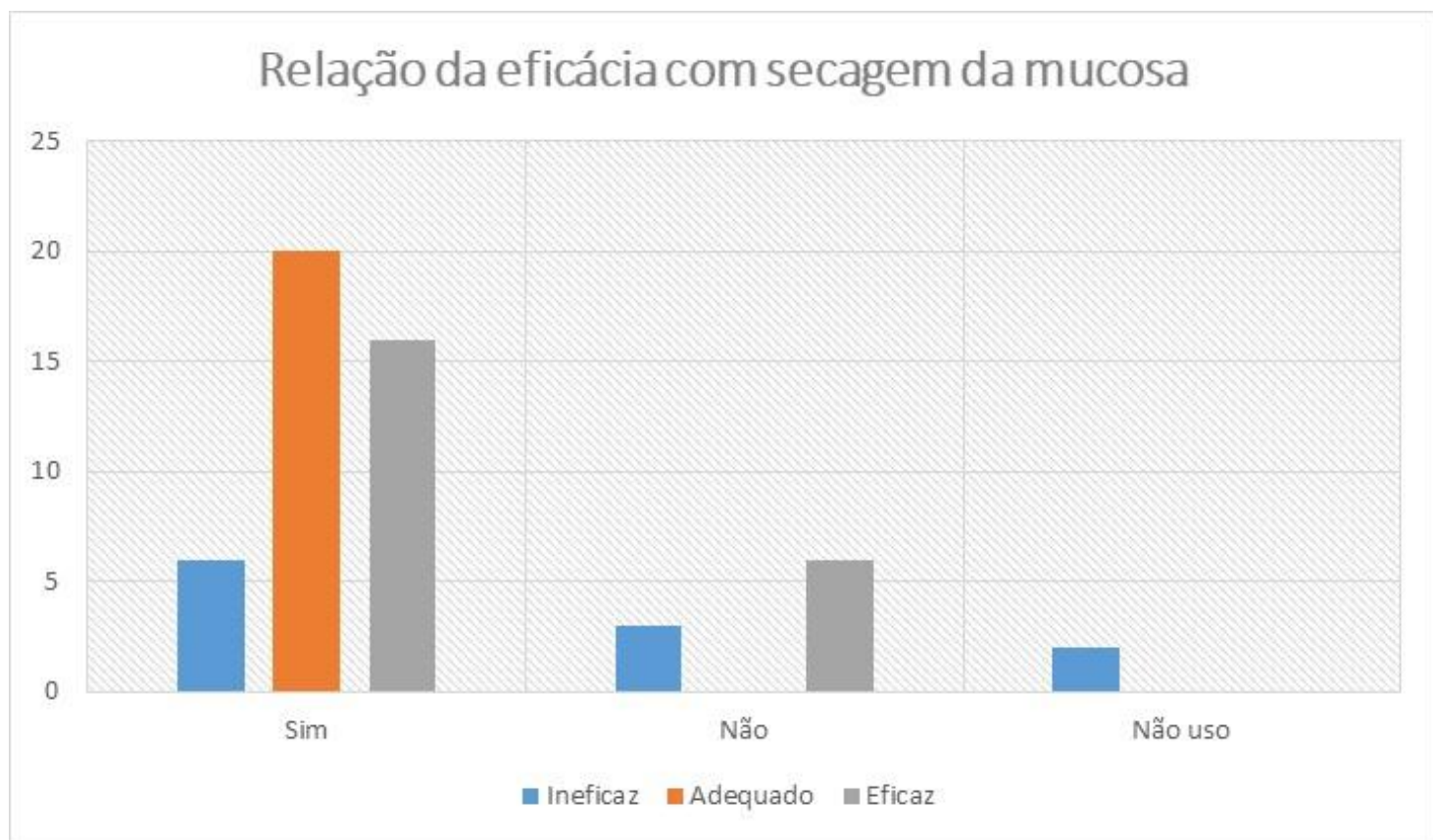

Figura 10. Relação eficácia com secagem da mucosa. 
Ainda sobre a eficácia conclui-se que quando se espera 60 segundos ou mais para efetuar a injeção anestésica essa taxa não aumenta, o que pode acabar fazendo com que o profissional não tenha uma resposta sobre o real efeito do produto (Figura 11). A respeito do grupo de pacientes, quando usados em crianças, os profissionais consideram menos eficaz que quando utilizados em adultos e pacientes ansiosos (Figura 12).

\section{Relação da eficácia com tempo de espera}

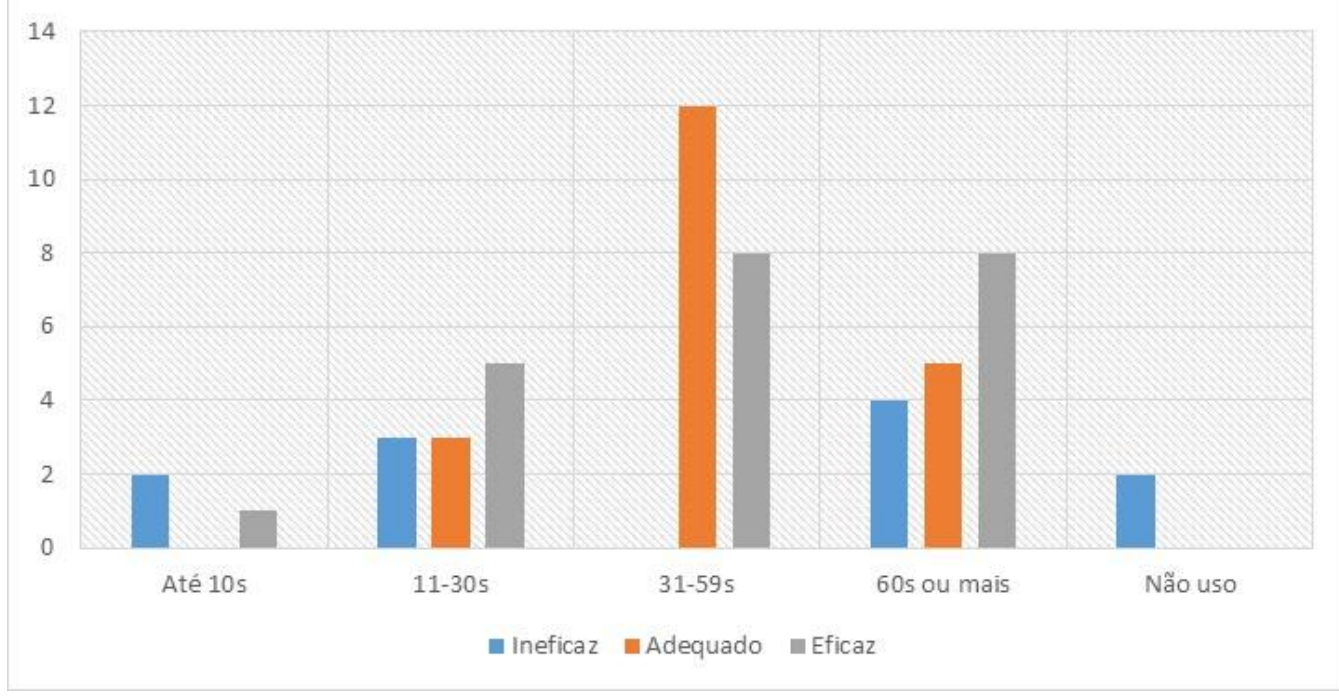

Figura 11. Relação eficácia com tempo de espera.

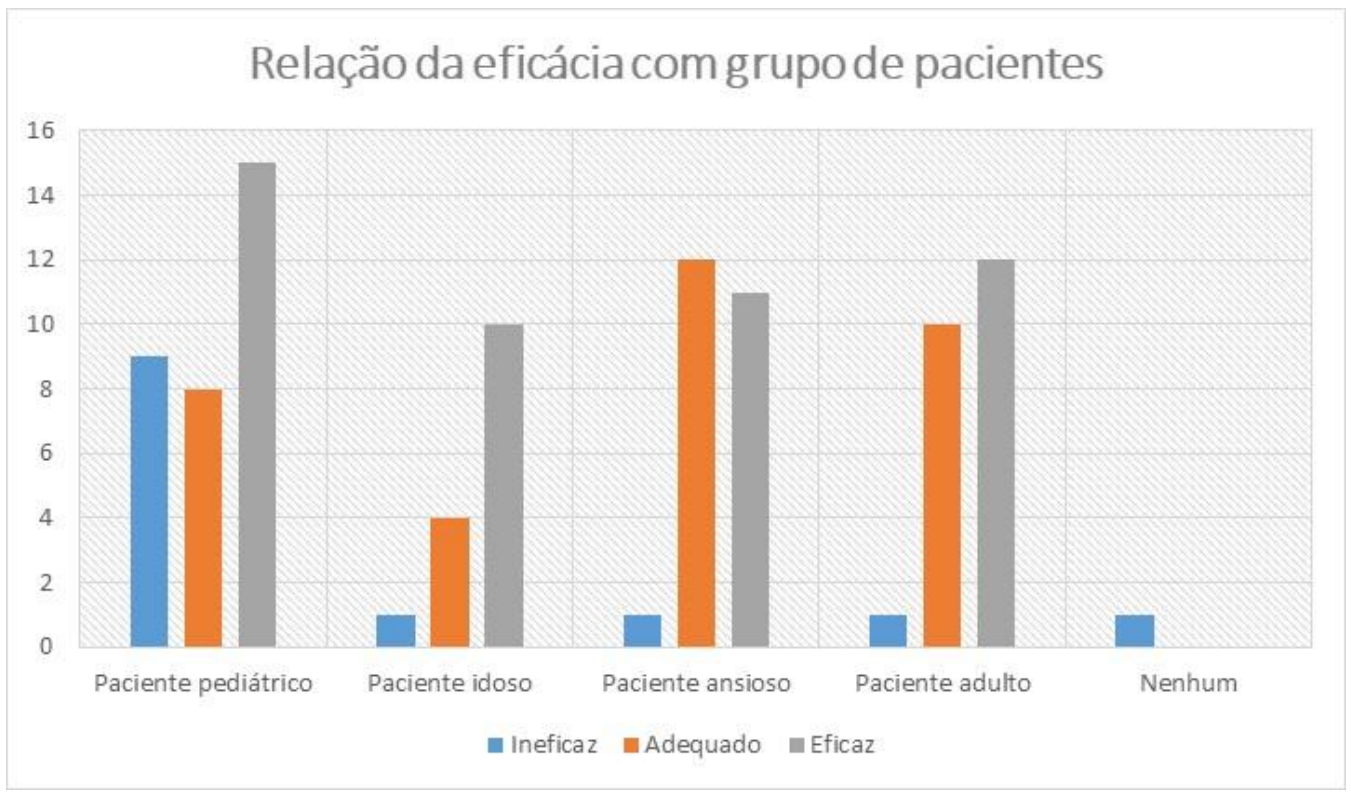

Figura 12. Relação eficácia com grupo de pacientes. 


\section{Discussão}

É essencial que os dentistas façam o possível para minimizar a dor e o desconforto durante $\mathrm{o}$ tratamento odontológico. Devido à possibilidade do paciente sentir desconforto durante procedimentos restauradores e cirúrgicos, os dentistas têm investido no uso de anestésicos locais para controlar a dor. O método mais simples e eficaz de reduzir a dor durante procedimentos odontológicos é por injeção de anestesia local e, a dor dessa injeção é minimizada com anestesia tópica [13], passo que é bastante utilizado pelos Cirurgiões Dentistas, como podemos observar no presente estudo, onde profissionais de diversas especialidades utilizam esse método.

Crout et al. [14] avaliou a eficácia dos anestésicos locais usados e descobriu que o EMLA é muito eficaz como creme tópico intraoral, apesar disso, o gel foi a forma de apresentação mais utilizada pelos entrevistados do presente estudo, com $89 \%$, enquanto que em uma pesquisa realizada por Dhindsa [15], essa porcentagem cai para $58 \%$.

Yen et al. [16] verificaram outros sistemas de anestesia local, onde dois estudos recentes avaliaram o efeito analgésico e a segurança do sistema de administração de lidocaína intrabucal, obtendo analgesia muito importante no processo de inserção da agulha, assim como a benzocaína, presente no produto mais utilizados pelo público alvo entrevistado na presente pesquisa, também desempenha um bom papel. Foi visto também que os anestésicos tópicos apresentam tanto benefícios farmacológicos como psicológicos [10], auxiliando bastante no atendimento de pacientes mais ansioso, que pode explicar o fato de $25 \%$ dos Cirurgiões Dentistas entrevistados utilizarem anestésicos tópicos em pacientes ansiosos, ficando atrás apenas da utilização em crianças, com $34 \%$.

É notório a contradição na literatura quando o assunto é o tempo de espera após a aplicação do AT. Alguns fabricantes indicam esperar $10 \mathrm{a}$ 30 segundos após a aplicação do AT, outros aproximadamente 30 segundos, enquanto Malamed [9] recomenda 60 segundos ou mais antes da injeção para assegurar que o produto seja mais eficaz [9]. Entre os profissionais que participaram do presente estudo, apenas $32 \%$ aguardavam mais de 60 segundos após a aplicação do AT, enquanto Naik [17], observou que apenas $8 \%$ dos dentistas aguardavam um período maior que 61 segundos. Esse fato pode prejudicar a eficácia do AT, haja visto que um período de espera maior está associado a uma maior penetração, podendo aumentar a efetividade da anestesia tópica [17].

Constata-se por meio desse estudo que a taxa de ineficácia dos anestésicos tópicos está mais associada a injeções da técnica terminal infiltrativa e na área palatina. Vários artigos avaliando anestésicos tópicos, observam 
que a região de mucosa palatina é a mais dolorosa no momento da infiltração local. Dessa forma, nota-se que a dor sentida no momento da punção é intimamente impactada pela região a ser anestesiada, já que as regiões palatina e anterior da maxila são muito desconfortáveis. Pesquisadores revelam que essa maior sensibilidade está ligada à rigidez e íntima ligação da mucosa do palato com o periósteo subjacente e seu farto suprimento nervoso [2].

A anestesia tópica deve ser aplicada após a secagem da mucosa oral onde a injeção será administrada, assim como $79 \%$ dos cirurgiões-dentistas que participaram dessa pesquisa já fazem. Usando um cotonete, aplica-se na quantidade mínima necessária para produzir efeito suficiente. Quando a superfície está seca, seu efeito é potencializado. Por esse motivo é importante que a mesma esteja adequadamente seca antes da administração. Normalmente, os agentes anestésicos tópicos são concentrados para facilitar a infiltração e assim ser necessário apenas uma fina camada, evitando casos de toxicidade [12].

Múltiplos fatores podem ser responsáveis por essa confusão referente à eficácia dos anestésicos tópicos em aliviar a dor da injeção, como: a distinção da área da aplicação, secagem preliminar da superfície, o tempo de aplicação, método de avaliação da dor, tipo de produto e a agulha utilizada.
Tudo isso, pode acabar influenciando no real efeito que a anestesia tópica promete cumprir, fazendo com que confunda o julgamento de sua eficácia [2].

Independente de inúmeros testes, é relevante salientar que até essa altura não há nenhum produto hábil a eliminar totalmente o incômodo provocado pela agulha, desta forma, alguns profissionais optam por não utilizar AT, já que não há uma analgesia total. Sendo assim, os profissionais de saúde, em especial dentistas, devem estar em pesquisas constantes para se atualizar sempre e, assim, proporcionar um atendimento mais seguro, confortável e livre de riscos [2].

\section{Conclusões}

A maioria dos profissionais faz uso da anestesia tópica, principalmente na forma de gel, se destacando os endodontistas, dentistas restauradores, ortodontistas e protesistas. Além disso, indivíduos com mais tempo de formados utilizam anestésicos tópicos mais frequentemente e da forma mais correta.

Existem falhas nos passos para aplicação do AT o que pode consequentemente influenciar na sua real efetividade, podendo fazer com que alguns profissionais não reconheçam os benefícios do mesmo. Entre essas falhas, podemos perceber que quando $o$ produto é aplicado em uma mucosa seca as chances de eficácia aumentam em relação a uma mucosa úmida. Outro 
achado importante é que em regiões mais rígidas, como o palato, e na técnica terminal infiltrativa, $\mathrm{o}$ produto não consegue cumprir muito bem o seu papel.

Dentre as limitações do presente trabalho, pode-se destacar que apesar do uso de questionários de forma online apresentar inúmeros benefícios, podem existir problemas técnicos como baixa qualidade de conexão, além da necessidade de familiaridade dos participantes com formulários eletrônicos, podendo explicar o número de participantes não ter sido tão expressivo.

$\mathrm{O}$ uso dos ATs se mostra essencial e de extrema importância no atendimento odontológico, especialmente em pacientes pediátricos e ansiosos, para que assim os procedimentos necessários sejam efetuados sem desconforto.

\section{Referências}

[1] Knackfuss AP, Costenaro RGS, Zanatta FB. Dor odontológica e indicadores de risco em jovens. RGO. Revista Gaúcha de Odontologia (Online). 2011; 59(2):185-191.

[2] Silva FB, Tuorto FR, Vasconcellos IP, Silva OCM, Resende RFB. Eficácia do anestésico tópico em odontologia: Revisão de literatura. Odonto. 2019; 27(54):1-10.

[3] Ando T, Shimoo Y, Nakasato M, Yoshida H. Development and Clinical Evaluation of New Topical Anesthetic
Formulations for Dental Care. Biol Pharm Bull. 2016;39(3):423-7. doi: 10.1248/bpb.b15-00380.

[4] Kumar M, Chawla R, Goyal M. Topical anesthesia. J Anaesthesiol Clin Pharmacol. 2015 Oct-Dec;31(4):450-6. doi: 10.4103/0970-9185.169049.

[5] de Freiras GC, Pozzobon RT, Blaya DS, Moreira CH. Efficacy of Benzocaine 20\% Topical Anesthetic Compared to Placebo Prior to Administration of Local Anesthesia in the Oral Cavity: A Randomized Controlled Trial. Anesth Prog. 2015 Summer;62(2):46-50. doi: 10.2344/0003-3006-62.2.46.

[6] Park L, Tom J, Bui N, Wilson M, Tanbonliong T. Comparing the Efficacy of a Compound Topical Anesthetic Versus Benzocaine: A Pilot Study. Anesth Prog. 2020 Spring;67(1):9-15. doi: 10.2344/anpr-66-03-05.

[7] DiMarco AC, Wetmore AO. Clinical Comparison: Fast-Acting and Traditional Topical Dental Anesthetic. Anesth Prog. 2016 Summer;63(2):55-61. doi: 10.2344/0003-3006-63.2.55.

[8] Franz-Montan M, Ribeiro LNM, Volpato MC, Cereda CMS, Groppo FC, Tofoli GR, de Araújo DR, Santi P, Padula C, de Paula E. Recent advances and perspectives in topical oral anesthesia. Expert Opin Drug Deliv. 2017 May;14(5):673-684. doi: 10.1080/17425247.2016.1227784. 
[9] Malamed SF. Manual de anestesia local. Elsevier Health Sciences, page 63, 2013.

[10] Dave PH, Prabu D. Survey among dentists about the use of topical anesthetics during administration of local anesthesia. Drug Invention Today. 2019;11(1).

[11] Cho SY, Kim E, Park SH, Roh BD, Lee CY, Lee SJ, Jung IY. Effect of Topical Anesthesia on Pain from Needle Insertion and Injection and Its Relationship with Anxiety in Patients Awaiting Apical Surgery: A Randomized Double-blind Clinical Trial. J Endod. 2017 Mar;43(3):364-369. doi: 10.1016/j.joen.2016.10.036.

[12] Lee HS. Recent advances in topical anesthesia. J Dent Anesth Pain Med. 2016 Dec;16(4):237-244. doi: 10.17245/jdapm.2016.16.4.237.

[13] Salma NA, Ramakrishnan M. Naurin. Use of anesthesia in pediatric dentistry: A cross-sectional survey. International Journal of Pedodontic Rehabilitation. 2016;1(1):5.

[14] Crout RJ et al. Clinical assessment of mandibular block techniques of US dentists. In: Journal of Dental Research. 1619 Duke St, Alexandria, Va 22314: Amer Assoc Dental Research, 1997. p. 809-809.

[15] Dhindsa A, Rani R, Chachra A, Chachra S, Shrikant K, Sharma M. Survey of usage and type of topical anesthesia among dentists of tricity. Int J Contemp Med Res. 2019;611-5.

[16] Second YLK, Neelakantan P. Local anesthetics in dentistry-newer methods of delivery. International Journal of Pharmaceutical and Clinical Research. 2014;6(01):04-06.

[17] Naik S, Chandak A, Vashisht P. The Use of Topical Anesthesia among Dentists: An Online Survey. Oral Rehabilitation. 2021;12(1):19.

Conflito de interesse: Os autores declaram não possuir conflito de interesse com o presente estudo.

Agradecimentos: Nenhum.

Financiamento: Nenhum.

Como citar este artigo: Araújo TJG, Albuquerque DF, Barroso MVB, Matos HL, Cavalcante IL, Medeiros JR, Viana FAC, Pereira SLS, Gusmão JNFM, Silva BFA. Avaliação do uso de anestésico tópico por cirurgiões dentistas professores de uma universidade particular do Nordeste Brasileiro. Brazilian Journal of Case Reports. 2021 Oct-Dec;01(4):160-174. 